\title{
PENGARUH ATTITUDE, SUBJECTIVE NORM, PAST BEHAVIOR, DAN PERCEIVED CONTROL TERHADAP BUDGETING INTENTION MAHASISWA DI SURABAYA
}

\author{
Jason Yulesviva Kurniawan ${ }^{{ }^{\star}}$, Mariana Ing Malelak ${ }^{2}$, Dewi Astuti ${ }^{3}$ \\ ${ }^{1,2,3}$ Program Finance \& Investment, Program Studi Manajemen \\ Fakultas Bisnis dan Ekonomi, Universitas Kristen Petra \\ Jl. Siwalankerto 121-131, Surabaya 60236 \\ E-mail: 1jasonyk97@gmail.com; ${ }^{2}$ mariana.ing@petra.ac.id; ${ }^{3}$ dewi@petra.ac.id \\ ${ }^{*}$ Penulis korespondensi
}

\begin{abstract}
ABSTRAK
Pengelolaan keuangan merupakan hal yang penting bagi seseorang dalam mengatur pengeluaran dan pemasukan. Keseimbangan antara pemasukan dan pengeluaran memberikan benefit bagi seseorang dalam menentukan attitude, subjective norm, past behavior, dan perceived control terhadap budgeting intention. Sampel dari penelitian ini merupakan 100 mahasiswa yang berasal dari luar Surabaya yang berkuliah di Surabaya dan memiliki tempat tinggal di rumah kontrakan atau tempat tinggal kos-kosan. Pengumpulan data dengan menggunakan kuisioner berupa pernyataan tertutup melalui google form. Metode yang digunakan pada penelitian ini adalah metode asosiatif-kuantitatif. Analisa yang digunakan dalam penelitian ini adalah analisa Partial Least Square-Structural Equation Modelling (PLS-SEM) dengan dibantu program aplikasi SmartPLS. Hasil penelitian menunjukkan bahwa attitude, subjective norm, past behavior, dan perceived control berpengaruh positif signifikan terhadap budgeting intention mahasiswa.
\end{abstract}

Kata kunci: Attitude, Budgeting Intention, Past Behavior, Perceived Behavior, Subjective Norm, Theory of Planned Behavior.

\section{ABSTRACT}

Financial management is important for someone in expenses and income. The balance between income and expenditure provides benefits for a person in determining attitudes, subjective norms, past behavior, and perceived control over budget intentions. The sample of this study is 100 students from outside Surabaya who study in Surabaya and have a place to live in a rented house or boarding house. Collecting data using a closed questionnaire through a google form. The method used in this research is associative-quantitative method. The analysis used in this study is the analysis of Partial Least Square-Structural Equation Modeling (PLS-SEM) with the help of the SmartPLS application program. The results showed that attitudes, subjective norms, past behavior, and perceptions of control had a significant positive effect on student budgeting intentions.

Keywords: Attitude, Budgeting Intention, Past Behavior, Perceived Behavior, Subjective Norm, Theory of Planned Behavior.

\section{PENDAHULUAN}

Sebanyak 20\% mahasiswa baru terpaksa puasa karena uangnya habis untuk membeli barang yang tidak diperlukannya (Mustafa, 2015). Kurangnya kemampuan dalam mengelola uang merupakan permasalahan utama terkait dengan hutang yang berlebihan (Knight \& Knight, 2000). Salah satu komponen penting dalam penerapan manajemen uang yang baik adalah dengan 
membuat budgeting. Penganggaran (budgeting) yang dimaksud adalah membuat anggaran pengeluaran beserta nominalnya guna mencapai keseimbangan antara pemasukan dan pengeluaran. Dengan membuat budgeting, pola pengeluaran individu akan lebih teratur dan dapat mencegah individu untuk berhutang atau terlilit hutang.

Penelitian ini mengukur pengaruh budgeting intention menggunakan Theory of Planned Behavior (TPB). Menurut Kidwell \& Turrisi (2004), ada empat faktor yang mempengaruhi budgeting intention (niat individu untuk membuat budgeting) yaitu sikap terhadap budgeting (attitude), perilaku masa lalu atau dapat disebut kebiasaan (past behavior), tekanan dari masyarakat (subjective norm), dan persepsi kontrol (perceived control). Sikap terhadap budgeting diukur dari lima hal yaitu consumption saliency, undesired effort, purchasing barriers, perceived knowledge, dan structured spending. Subjective norm merupakan pengaruh atau tekanan dari orang-orang terdekat. Past behavior dinilai dari perilaku masa lalu, dan perceived control dilihat dari tingkat kontrol persepsi individu terhadap suatu perilaku.

Berdasarkan hasil pre-survey yang dilakukan pada sepuluh mahasiswa yang berkuliah di Surabaya, uang saku yang diterima bervariasi mulai dari Rp 1.500 .000 sampai Rp 7.000 .000 per bulan. Lima dari sepuluh orang mahasiswa melakukan budgeting dan lima dari sepuluh orang mahasiswa tidak melakukan budgeting. Mahasiswa yang melakukan budgeting merupakan individu yang peduli kepada pengelolaan keuangan. Bagi mahasiswa yang tidak melakukan budgeting, hal itu didorong oleh kurangnya minat untuk membuat budgeting, tidak terbiasa melakukan budgeting, dan merasa bahwa membuat budgeting merupakan hal yang susah untuk dilakukan.

Mahasiswa yang berkuliah di luar kota kelahirannya dipaksa untuk hidup mandiri. Hidup jauh dari orang tua dan harus menetap sendiri di kota tertentu membuat tempat kos menjadi salah satu pilihan mahasiswa untuk tinggal karena dinilai lebih praktis dan lokasinya yang relatif dekat dengan kampus. Hidup mandiri membuat mahasiswa harus bisa memperhitungkan uang yang diberikan oleh orang tua agar dapat mencukupi semua kebutuhannya. Permasalahan ini mendorong peneliti untuk melakukan penelitian tentang budgeting intention yang dipengaruhi oleh faktor psikologis individu berdasarkan Theory of Planned Behavior (TPB) yaitu attitude, subjective norm, past behavior, dan perceived control.

\section{TEORI PENUNJANG}

\section{Money Management}

Money management adalah kemampuan individu dalam mengatur perencanaan, penganggaran, pengelolaan, pemeriksaan, pencarian, pengendalian, dan penyimpanan dana keuangan seharihari. Money management muncul karena besarnya hasrat individu untuk memenuhi kebutuhan hidupnya sesuai dengan tingkat pendapatan yang diperoleh (Kholilah \& Iramani, 2013).

\section{Budgeting Intention}

Menurut Kamus Besar Bahasa Indonesia, penganggaran (budgeting) adalah proses membuat rancangan pengeluaran dan penerimaan keuangan selama jangka waktu tertentu. Menurut Johnson (1984), penganggaran memiliki arti yaitu teknik untuk menyelesaikan masalah keuangan rumah tangga yang kompleks. 
Menurut Fishbein \& Ajzen (1975) berdasarkan Theory of Reasoned Action (TRA), intention atau niat adalah usaha yang disadari untuk mencapai tujuan atau sasaran yang telah didefinisikan secara jelas. Menurut Ajzen (2012) pada Theory of Planned Behavior (TPB) yang merupakan pengembangan dari TRA, intention adalah keinginan untuk melakukan perilaku tertentu. Intention merupakan indikasi untuk mengetahui seberapa besar usaha yang akan dikeluarkan individu untuk melakukan perilaku. Dapat diartikan bahwa budgeting intention adalah niat individu untuk membuat budgeting.

\section{Theory of Planned Behavior}

Theory of Planned Behavior (TPB) adalah pengembangan dari Theory of Reasoned Action (TRA). Theory of Reasoned Action (TRA) menjelaskan bahwa perilaku merupakan tindakan yang dilakukan karena individu memiliki keinginan atau niat untuk melakukannya. Di dalam TRA, belum diterapkan variabel perceived control. TPB mendeteksi bahwa tidak semua perilaku dilakukan dibawah kendali individu, sehingga perceived control ditambahkan untuk melengkapi itu. Apabila perilaku dapat dikendalikan secara penuh oleh individu, maka TPB akan kembali menjadi TRA (Ajzen, 2012). Keputusan untuk melakukan perilaku perlu dipertimbangkan, konsekuensi dari setiap perilaku akan dievaluasi hingga diputuskan apakah akan bertindak atau tidak. TPB menjelaskan tindakan individu yang didasari oleh tiga kepercayaan, yaitu

a. Behavioral beliefs, yaitu keyakinan individu mengenai konsekuensi positif dan atau negatif yang akan diperoleh individu dari melakukan perilaku (Ajzen, 2005).

b. Normative beliefs, yaitu keyakinan mengenai kesetujuan dan atau ketidaksetujuan sesorang maupun kelompok yang penting bagi individu terhadap perilaku (Ajzen, 2005).

c. Control beliefs, yaitu keyakinan individu mengenai faktor pendukung dan atau penghambat untuk melakukan perilaku (Ajzen, 2005)

\section{Attitude}

Hartono (2007) mendefinisikan sikap sebagai tanggapan dan keyakinan individu terhadap sesuatu yang bersifat menguntungkan atau tidak menguntungkan untuk melakukan perilaku yang akan ditentukan.

a. Consumption Saliency

Membuat budgeting dapat meningkatkan kewaspadaan individu terhadap akibat dari konsumsi yang berlebihan (Heath \& Soll, 1996). Semakin individu merasa bahwa budgeting meningkatkan kewaspadaan terhadap akibat dari konsumsi yang berlebihan, maka individu cenderung memiliki good budgeting attitude.

b. Undesired Effort

Menurut Bagozzi \& Kimmel (1995) dan Triandis (1997), kinerja akan meningkat apabila tidak adanya pengaruh eksternal yang bertindak menjadi penghambat. Karena itu, semakin individu merasa bahwa membuat budgeting memerlukan effort yang besar seperti ketelitian, menyita waktu, dsb, maka individu cenderung memiliki bad budgeting attitude.

c. Purchase barriers

Penelitian dari Dittmar, Beattie, \& Friese (1995) menunjukkan bahwa pembelian impulsif berpengaruh negatif terhadap pengelolaan keuangan. Dengan demikian, semakin individu merasa bahwa budgeting dapat menjadi penghambat dalam melakukan pembelian impulsif, maka individu cenderung memiliki bad budgeting attitude.

d. Perceived Knowledge 
Individu yang merasa memiliki kurang pengetahuan tentang budgeting akan memiliki motivasi yang lebih besar untuk membuat budgeting. Motivasi untuk membuat budgeting ini membuat individu cenderung memiliki good budgeting attitude.

e. Structured Spending

Penelitian Heath \& Soll (1996) menyebutkan bahwa ketika individu konsisten menyusun budgeting, pola pengeluaran dapat berubah menjadi lebih baik dan teratur. Oleh karena itu, individu akan cenderung memiliki good budgeting attitude apabila individu berpikir bahwa budgeting dapat membatasi pengeluaran yang tidak diperlukan.

\section{Subjective Norm}

Subjective norm adalah pengaruh atau tekanan dari pihak luar terhadap individu untuk melakukan kegiatan tertentu (Hartono, 2007). Ajzen (2005) mengatakan subjective norm didasari oleh keyakinan atau belief yang disebut normative belief, yaitu norma yang dibentuk oleh orang lain atau kelompok yang berpengaruh bagi individu, seperti keluarga, teman, dan orang yang dianggap penting (role model).

\section{Past Behavior}

Menurut Joko (2008), kebiasaan merupakan perbuatan yang dilakukan manusia secara berulangulang dengan cara yang sama. Menurut Sayid (2006), kebiasaan adalah pengulangan perilaku secara terus-menerus atau dalam sebagian besar waktu dengan cara yang sama dan tanpa hubungan akal, atau yang tertanam di dalam jiwa. Menurut Kamus Besar Bahasa Indonesia, pengalaman merupakan hal yang pernah dilakukan (dialami, dijalani, dirasai, ditanggung). Dapat dimpulkan bahwa past behavior adalah perilaku yang dilakukan oleh manusia pada masa lalu yang dapat dijadikan pembelajaran atau pertimbangan untuk melakukan hal di masa yang akan datang.

\section{Perceived Control}

Perilaku yang dilakukan individu tidak hanya dikendalikan oleh dirinya sendiri, tetapi juga melibatkan kontrol seperti ketersediaan sumber daya dan kesempatan bahkan keterampilan tertentu (Ismail \& Zain, 2008). Perceived control merepresentasikan kepercayaan individu tentang seberapa mudah individu melakukan perilaku. Ketika individu percaya bahwa dirinya kekurangan sumber daya atau tidak memiliki kesempatan untuk melakukan perilaku, maka individu akan memiliki intensi yang rendah untuk melakukan perilaku tersebut (Engel, Blackwell, \& Miniard, 1995).

\section{Pengaruh Attitude terhadap Budgeting Intention}

Jika mahasiswa memandang bahwa budgeting memberikan manfaat bagi dirinya, hal ini akan membentuk sikap positif mahasiswa pada budgeting, yang selanjutnya akan meningkatkan niatnya untuk membuat budgeting. Sebaliknya, jika mahasiswa memandang bahwa budgeting tidak terlalu memberikan manfaat bagi dirinya, hal tersebut akan membentuk sikap negatif, yang selanjutnya akan menurunkan niatnya untuk membuat budgeting.

\section{Pengaruh Subjective Norm terhadap Budgeting Intention}

Pihak luar yang berpandangan bahwa membuat budgeting akan memberikan manfaat bagi mahasiswa akan cenderung menyarankan mahasiswa tersebut untuk membuat budgeting. Jika 
mahasiswa tersebut sependapat dengan pandangan pihak luar, hal tersebut akan meningkatkan niatnya untuk membuat budgeting Sebaliknya, jika terdapat perbedaan pendapat dengan pandangan pihak luar, hal tersebut akan menurunkan niatnya untuk membuat budgeting.

\section{Pengaruh Past Behavior terhadap Budgeting Intention}

Penelitian Knowles, Hyde, \& White (2012) menjelaskan bahwa past behavior memiliki pengaruh yang kuat kepada future behavior. Oleh karena itu, dapat diartikan bahwa past behavior mahasiswa dalam membuat budgeting dapat memberikan pengaruh untuk membuat budgeting lagi di masa yang akan datang.

\section{Pengaruh Perceived Control terhadap Budgeting Intention}

Jika mahasiswa mempersepsikan bahwa ia mampu mengatasi kesulitan dalam membuat budgeting, hal ini akan meningkatkan niatnya untuk membuat budgeting. Sebaliknya, jika mahasiswa mempersepsikan bahwa ia tidak memiliki kemampuan yang cukup untuk mengatasi kesulitan dalam membuat budgeting, hal tersebut akan menurunkan niatnya untuk membuat budgeting.

\section{Kerangka Berpikir}

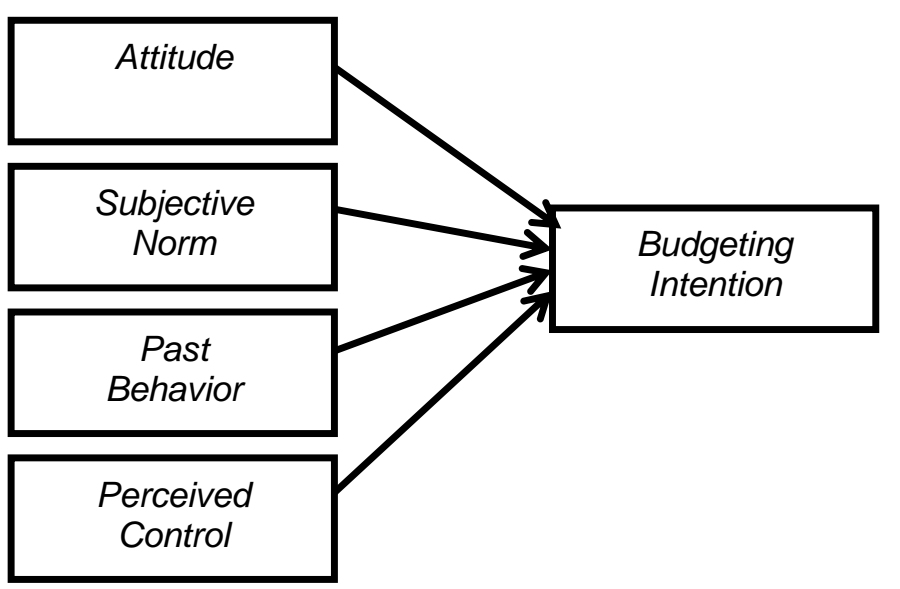

\section{Hipotesa}

1. Attitude berpengaruh signifkan terhadap budgeting intention mhasiswa di Surabaya

2. Subjective norm berpengaruh signifkan terhadap budgeting intention mhasiswa di Surabaya

3. Past Behavior berpengaruh signifkan terhadap budgeting intention mhasiswa di Surabaya

4. Perceived Control berpengaruh signifkan terhadap budgeting intention mhasiswa di Surabaya

\section{METODE PENELITIAN}

Penelitian asosiatif dengan menggunakan pendekatan kuantitatif merupakan jenis penelitian ini. Penelitian asosiatif adalah metode penelitian yang dilakukan untuk menghubungkan variabel satu dengan variabel yang lain dengan tujuan untuk mengetahui pengaruh antar variabel (Supriyanto, 2009). Penelitian kuantitatif merupakan metode yang digunakan untuk menampilkan hasil penelitian dalam bentuk statistik (Sugiyono, 2007). Teknik sampling yang digunakan adalah purposive sampling, Purposive sampling digunakan untuk mendapatkan sasaran yang diinginkan. 
Kriteria yang telah ditentukan yakni:

1. Mahasiswa dari luar Surabaya yang berkuliah di Surabaya

2. Mahasiswa yang bertempat tinggal di kos

Penelitian ini menggunakan data primer. Menurut Sugiyono (2014), data primer merupakan data yang dikumpulkan oleh peneliti langsung dari sumber penelitian yang dilakukan. Sumber data penelitian ini berasal dari responden yang mengisi kuesioner.

\section{Variabel Dependen}

Variabel dependen dalam penelitian ini adalah budgeting intention (BI). BI merupakan keinginan untuk membuat rancangan pengeluaran dan penerimaan keuangan selama jangka waktu tertentu (Ajzen, 2012). Indikator dari variabel ini yaitu intend to, plan to, dan try to.

\section{Variabel Independen}

Variabel independen yang digunakan dalam penelitian ini:

\section{a. Attitude}

Tanggapan dan keyakinan individu terhadap perilaku yang bersifat menguntungkan atau tidak menguntungkan untuk melakukan budgeting (Hartono, 2007) (Kidwell \& Turrisi, 2004). Indikator empirik dari variabel ini yaitu consumption saliency, undesired effort, purchase barriers, perceived barriers, perceived knowledge, dan structured spending.

b. Subjective Norm

Pengaruh atau tekanan dari pihak luar terhadap individu untuk membuat budgeting (Hartono, 2007) (Kidwell \& Turrisi, 2004). Indikator empirik dari variabel ini yaitu mendapatkan saran, menerima saran, dan mengharapakan dukungan.

c. Past Behavior

Perilaku yang dilakukan pada masa lalu yang dapat dijadikan pembelajaran atau pertimbangan untuk melakukan budgeting di masa yang akan datang (Knowles, Hyde, \& White, 2012) (Kidwell \& Turrisi, 2004). Indikator empirik dari variabel ini yaitu habbit, frequency, dan recency.

d. Perceived Control

Persepsi individu mengenai kontrol yang dimiliki sehubungan dengan membuat budgeting (Ismail \& Zain, 2008) (Kidwell \& Turrisi, 2004). Indikator empiric dari variabel ini yaitu percaya memiliki kemampuan, percaya mampu membuat, yakin dengan kemampuan, dan yakin akan mampu membuat.

\section{Teknik Analisa Data}

Teknik yang digunakan untuk mengolah data dalam penelitian ini yaitu :

1. Mengumpulkan kuesioner yang sudah diisi oleh responden kemudian mengambil data yang sesuai untuk dipergunakan dalam penelitian. Data yang sudah terkumpul selanjutnya akan diolah menggunakan metode PLS - SEM melalui program smartPLS.

2. Evaluasi outer model untuk menguji validitas dan reliabilitas yaitu dengan melihat hasil convergent validity, discriminant validity, dan composite reliability.

3. Evaluasi inner model dengan cara melihat nilai $r$-square untuk melihat pengaruh variabel dependen terhadap independen 


\section{ANALISA DAN PEMBAHASAN}

Hasil pengumpulan data menunjukkan bahwa 100 responden dari penelitian ini memiliki rata-rata nilai attitude sebesar 3.83 yang berarti sebagian besar responden memiliki tingkat attitude yang baik, subjective norm sebesar 3.71 yang berarti sebagian besar responden merasakan adanya pengaruh subjective norm, past behavior sebesar 3.92 yang berarti sebagian besar responden pernah membuat budgeting, perceived control sebesar 3.76 yang berarti sebagian besar responden memiliki tingkat persepsi kontrol yang tinggi, dan budgeting intention sebesar 3.94 yang berarti sebgian besar responden memiliki niat yang tinggi untuk membuat budgeting.

Hasil pengolahan data pertama menggunakan metode PLS-SEM memberikan hasil untuk menghapus 4 indikator dari attitude dan 1 indikator dari subjective norm karena memiliki nilai loading factor kurang dari 0.5. Setelah menghapus indikator tersebut, setiap indikator sudah memiliki nilai loading factor lebih dari 0.5 yang berarti indikator-indikator dalam penelitian ini sudah memenuhi syarat convergent validity.

Nilai cross loading dari masing-masing indikator lebih tinggi pada variabelnya disbanding dengan variabel lain. Maka dapat dinyatakan bahwa data penelitian ini telah memenuhi syarat discriminant validity.

Tabel 1. Average Variance Extracted (AVE)

\begin{tabular}{lc}
\hline \multicolumn{1}{c}{ Variabel } & AVE \\
\hline Attitude & 0.598 \\
Subjective Norm & 0.857 \\
Past Behavior & 0.660 \\
Perceived Control & 0.733 \\
Budgeting Intention & 0.660 \\
\hline
\end{tabular}

Tabel 1 menunjukkan nilai AVE setiap variabel lebih besar dari 0.5 yang berarti variabel dalam penelitian ini sudah memenuji syarat uji discriminant validity.

Tabel 2. Cronbach's Alpha

\begin{tabular}{lc}
\hline \multicolumn{1}{c}{ Variabel } & Cronbach's Alpha \\
\hline Attitude & 0.866 \\
Subjective Norm & 0.834 \\
Past Behavior & 0.742 \\
Perceived Control & 0.817 \\
Budgeting Intention & 0.743 \\
\hline
\end{tabular}

Tabel 2 menunjukkan nilai Cronbach's Alpha setiap variabel lebih dari 0.7 yang berarti variabel dalam penelitian ini sudah memenuhi uji reliabilitas.

Tabel 3. Composite Reliability

\begin{tabular}{lc}
\hline \multicolumn{1}{c}{ Variabel } & Composite Reliability \\
\hline Attitude & 0.899 \\
Subjective Norm & 0.923 \\
Past Behavior & 0.853 \\
Perceived Control & 0.892 \\
Budgeting Intention & 0.853 \\
\hline
\end{tabular}


Tabel.3 menunjukkan nilai Composite Reliability setiap variabel lebih dari 0.7 yang berarti variabel dalam penelitian ini mempunyai reliabilitas yang baik.

Tabel 4. R-Square

\begin{tabular}{cc}
\hline Variabel & R-Square \\
\hline Budgeting Intenion & 0.647 \\
\hline
\end{tabular}

Tabel 4 menunjukkan nilai $r$-square untuk variabel budeting intention sebesar 0.644 , memiliki arti bahwa variabel budgeting intention dapat dijelaskan oleh variabel attitude, subjective norm, past behavior, dan perceived control sebesar 64.4 persen, sedangkan sisanya yaitu 35.6 persen dijelaskan oleh variabel-variabel lain diluar penelitian ini.

Tabel 5. $t$-statistics

\begin{tabular}{clcc}
\hline Hipotesis & \multicolumn{1}{c}{ Pengaruh Antar Variabel } & Koefisien & t-statistics \\
\hline H1 & Attitude -> Budgeting Intention & 0.160 & 2.110 \\
H2 & Subjective Norm -> Budgeting Intention & 0.343 & 5.283 \\
H3 & Past Behavior -> Budgeting Intention & 0.241 & 3.343 \\
H4 & Perceived Control -> Budgeting Intention & 0.363 & 4.532 \\
\hline
\end{tabular}

Tabel 5 menunjukkan nilai koefisien dan t-statistics dari $\mathrm{H} 1, \mathrm{H} 2, \mathrm{H} 3$, dan $\mathrm{H} 4$. $\mathrm{H} 1$ menunjukkan nilai koefisien positif dan $t$-statistics lebih besar dari 1.96 yang memiliki arti attitude berpengaruh signifikan positif terhadap budgeting intention. $\mathrm{H} 2$ menunjukkan nilai koefisien positif dan $t$ statistics lebih besar dari 1.96 yang memiliki arti subjective norm berpengaruh signifikan positif terhadap budgeting intention. H3 menunjukkan nilai koefisien positif dan $t$-statistics lebih besar dari 1.96 yang memiliki arti past behavior berpengaruh signifikan positif terhadap budgeting intention. $\mathrm{H} 1$ menunjukkan nilai koefisien positif dan $t$-statistics lebih besar dari 1.96 yang memiliki arti perceived control berpengaruh signifikan positif terhadap budgeting intention.

\section{KESIMPULAN}

Hasil analisis yang dilakukan dalam penelitian ini maka dapat ditetapkan beberapa kesimpulan sebagai berikut: Attitude berpengaruh positif signifikan terhadap budgeting intention mahasiswa dari luar Surabaya yang berkuliah di Surabaya. Semakin baik attitude mahasiswa terhadap budgeting, maka semakin tinggi niat mahasiswa untuk membuat budgeting. Subjective norm berpengaruh positif signifikan terhadap budgeting intention mahasiswa dari luar Surabaya yang berkuliah di Surabaya. Semakin adanya tekanan sosial tentang membuat budgeting, maka akan semakin tinggi niat mahasiswa untuk membuat budgeting. Past behavior berpengaruh positif signifikan terhadap budgeting intention mahasiswa dari luar Surabaya yang berkuliah di Surabaya. Semakin sering mahasiswa membuat budgeting, maka akan semakin tinggi niat mahasiswa untuk membuat budgeting. Perceived Control berpengaruh positif signfikan terhadap budgeting intention mahasiswa dari luar Surabaya yang berkuliah di Surabaya, Semakin baik tingkat perceived control mahasiswa untuk membuat budgeting, maka akan semakin tinggi niat mahasiswa untuk membuat budgeting. Dalam memperbaiki penelitian ke depan maka perlu dilakukan mahasiswa membuat budgeting bagi mahasiswa merupakan hal yang sangat penting, khususnya bagi mahasiswa dari luar kota yang tinggal sendiri untuk berkuliah dan hanya mengandalkan uang kiriman dari orang tua untuk memenuhi kebutuhan hidup. Diperlukan edukasi sejak dini tentang pentingnya budgeting agar mahasiswa dapat mengatur keuangannya dengan baik sehingga tidak menimbulkan hal-hal yang tidak diinginkan. 


\section{DAFTAR PUSTAKA}

Ajzen, I. (2005). Attitudes, Personality, and Behavior. Berkshire, UK: Open University Press-McGraw Hill Education.

Ajzen, I. (2012). The Theory of Planned Behavior. In P. A. Van Lange, A. W. Kruglanski, \& E. T. Higgins, Handbook of Theories of Social Psychology (pp. 438-459). New York: Lawrence Erlbaum Associates.

Bagozzi, R., \& Kimmel, S. K. (1995). A Comparison of Leading Theories for Prediction of Goal-Directed Behaviours. British Journal of Social Psychology , 437-461.

Dittmar, H., Beattie, J., \& Friese, S. (1995). Gender identity and material symbols: Objects and decision considerations in impulse purchases. Journal of Economic Psychology , 491-511.

Engel, F. J., Blackwell, D. R., \& Miniard, P. W. (1995). Consumer Behavior (Vol. 8). Ohio: Thomson/SouthWestern.

Fishbein, M. A., \& Ajzen, I. (1975). Belief, attitude, intention and behaviour: An introduction to theory and research. MA: Addison-Wesley.

Hartono, J. (2007). Sistem Informasi Keperilakuan. ANDI. Yogyakarta.

Heath, C., \& Soll, J. B. (1996). Mental Budgeting and Consumer Decisions. Journal of Consumer Research, 23(1), 40-52.

Ismail, V. Y., \& Zain, E. (2008). Peranan Sikap, Norma Subjektif, dan Perceived Behavior Control terhadap Intensi Pelajar SLTA untuk memilih Fakultas Ekonomi. Jurnal Ekonomi dan Bisnis , 5, 3.

Johnson, M. D. (1984). Consumer Choice Strategies for Comparing Noncomparable Alternatives. Journal of Consumer Research , 11(3), 741-753.

Joko. (2008). Strategi Belajar Mengajar. Surakarta: FKIP UMS.

Kholilah, N. A., \& Iramani, R. (2013). Studi Financial Management Behavior pada Masyarakat Surabaya. Journal of Business and Banking , 3(1), 69-80.

Kidwell, B., \& Turrisi, R. (2004). An examination of college student money management tendencies. Journal of Economic Psychology , 25(5), 601-616.

Knight, L. G., \& Knight, R. A. (2000). Counseling Clients on Credit. Journal of Accountancy , 2, 61-72.

Knowles, S. R., Hyde, M. K., \& White, K. M. (2012). Predictors of Young People's Charitable Intentions to Donate Money: An Extended Theory of Planned Behavior Perspective. Journal of Applied Social Psychology , 42(9).

Mustafa, A. (2015). Kesalahan Mengelola Uang Para Mahasiswa Rantau. Retrieved 2020, from CNN Indonesia: https://www.cnnindonesia.com/gaya-hidup/20150906194659-277-76968/kesalahan-mengelola-uang-para-mahasiswa-rantau

Sayid, M. (2006). Pendidikan Remaja Antara Islam dan IImu Jiwa. Jakarta: Gema Insani Press.

Sugiyono. (2007). Metode Penelitian Administrasi Dilengkap dengan Metode R\&D (Vol. 15). Bandung: CV Alfabeta.

Sugiyono. (2014). Metode Penelitian Kuantitatif, Kualitatif, dan R\&D. Bandung: CV Alfabeta.

Supriyanto. (2009). Metodologi Riset Bisnis. Jakarta, Indonesia: PT. Indeks. 